\title{
ROGUE STATES AS THE STIGMATIZED MEMBERS OF INTERNATIONAL SOCIETY
}

\author{
Gleb V. Kotsur \\ Saint Petersburg State University, Saint Petersburg, Russian Federation
}

\begin{abstract}
At the turn of the century, the rogue state concept has become an integral part of the theory of international relations. However, even contemporary approaches lack the appropriate academic tools to reach a comprehensive understanding of the international community's role in determining the normative frameworks of the proper behavior of the states as the main actors of international system, leaving the relations between global community and the rogues almost an uncharted territory on the international stage. The article considers the category of rogue states as "excluded" members of the international community through the sociological lens of "stigma" (E. Goffman) and "labelling theory" (H. Becker and E. Lemert). Engaging an empirical case of Iraqi foreign policy during and after the Gulf War 1991, the author demonstrates two thresholds of the labelling state as the rogue: public initiation of the offender and self-fulfilling prophecy. It is possible to define some specific features of the outsider's behavior on the international stage: the high level of cooperation among the representatives of the same category, "unsustainable bravado" as the set of fluid and inconsistent actions of the rogue state in foreign policy, finally, the tendency toward obtaining the "secondary gains". Contrariwise, global community tends to pay greater attention to rogue states and exercise some discrimination practices on the ground of their outcast position in the world normative structure with the category of "wise" actors, for example China, being an exception from the common mainstream and maintaining close cooperation ties with rogues.

Key words: sociology of international relations, theory of international relations, rogue states, world order, constructivism, stigma.

Citation. Kotsur G.V. Rogue states as the stigmatized members of international society. Vestnik Volgogradskogo gosudarstvennogo universiteta. Serija 4, Istorija. Regionovedenie. Mezhdunarodnye otnoshenija [Science Journal of Volgograd State University. History. Area Studies. International Relations], 2017, vol. 22, no. 2, pp. 149-158. (in Russian).
\end{abstract}

УДК 327.8

Дата поступления статьи: 13.11.2016

ББК 66.4(0) Дата принятия статьи: 02.04.2017

\section{«СТРАНЫ-ИЗГОИ» КАК СТИГМАТИЗИРОВАННЫЕ ЧЛЕНЫ МЕЖДУНАРОДНОГО СООБЩЕСТВА}

\author{
Глеб Владиславович Коцур \\ Санкт-Петербургский государственный университет, г. Санкт-Петербург, Российская Федерация
}

\footnotetext{
Аннотация. Статья рассматривает категорию «стран-изгоев» в качестве «отверженных» членов мирового сообщества через призму социологических концепций «стигмы» И. Гофмана и теории «клеймения» Г. Беккера и Э. Лемерта. Подобный подход открывает возможности для выявления двух порогов включения ح государства в группу «изгоев»: «публичной инициации» нарушителя и «самовоспроизводящегося проро尺े чества», вследствие пересечения которых формируется девиантная карьера актора. Среди характерных повеюे денческих характеристик аутсайдера можно выделить высокую степень кооперации с представителями собственной категории, «неустойчивую браваду» и стремление к получению вторичных выгод, связанных со стигматизированным статусом. В свою очередь глобальное сообщество (за исключением группы «понимающих») склонно к проявлению повышенного внимания к «изгоям» и их дискриминации на основе ненорма(?) тивного положения в международной структуре.
} 
Ключевые слова: социология международных отношений, теория международных отношений, «страны-изгои», мировой порядок, конструктивизм, стигма.

Цитирование. Коцур, Г. В. «Страны-изгои» как стигматизированные члены международного сообщества / Г. В. Коцур // Вестник Волгоградского государственного университета. Серия 4, История. Регионоведение. Международные отношения. - 2017. - Т. 22, № 2. - С. 149-158.

На рубеже столетий концепция «странизгоев» (rogue states) стала неотъемлемой частью теоретического арсенала исследователей международных отношений, отразив политическую значимость категории в академическом и публицистическом дискурсе. В течение последних десятилетий предпринимаются многочисленные попытки исключить определенные государства из мирового сообщества на основании их несоответствия нормативным стандартам, сконструированным Западом. Более того, после событий украинского кризиса 2014 г. США и их союзники предпринимали активные, но не увенчавшиеся успехом попытки включения России в ряд «изгоев».

Ангажированность с одной стороны и социетальный характер наполнения данных категорий с другой обусловливают необходимость трансфера эпистемологических моделей из социологии для определения роли сообщества государств в конституировании понятия «стран-изгоев», а также достижения более комплексного осмысления их поведения на международной арене. Равным образом демонстрируемая по отношению к аутсайдерам ( акторам, исключенным или вынужденным занимать маргинальное положение в сообществе) дискриминация отсылает к социологическому наследию исследования стигматизации и девиации. Теория «клеймения» Г. Беккера [3] представляется продуктивной благодаря выделению двух порогов при включении агента в группу «отверженных» - «публичной инициации девианта» и «самовоспроизводящегося пророчества», что может быть продемонстрировано на примере присваивания Ираку Саддама Хуссейна статуса «изгоя» после оккупации Кувейта в 1991 году. В свою очередь детально разработанное И. Гофманом понятие «стигмы» [14] способно расширить границы академического знания в теории международных отношений за счет выделения американским социологом ряда черт и поведенческих характеристик стигматизи- рованного члена сообщества. Термины «своих» и «понимающих», «неустойчивой бравады» и «получения вторичных выгод» не только находят эмпирическое подтверждение при анализе внешнеполитического курса «изгоев», но и располагают потенциалом для заполнения ранее проигнорированных теоретиками международных отношений лакун при осмыслении интеракции между инсайдерами и аутсайдерами международного сообщества государств.

Появившись в словарях исследователеймеждународников в конце холодной войны [1], концепция «стран-изгоев» оказалась обойдена вниманием классиков теории международных отношений. К немногочисленным исключениям из этого правила можно отнести обладающую заметным нормативным измерением теорию демократического мира М. Дойла, относящую либерально-демократические стандарты в разряд эталонных, а автократические режимы - несовершенных и опасных как для своего населения, так и международного окружения [11].

Однако наибольший вклад в исследование оси взаимодействия инсайдеров и аутсайдеров мирового порядка (конкретной, в текущий исторический момент либерально-демократической конфигурации мирового сообщества) внесли представители тех направлений теории международных отношений, которые включают социальное измерение в анализ рассматриваемых явлений. Так один из основателей Английской школы международных отношений X. Булл занимался разработкой продуктивных для рассматриваемой проблематики понятий «международного общества государств» и «международного порядка». По замечанию Х. Булла, «общество» или синонимически используемое им «международное сообщество» [5, p. 230] существует тогда, когда государства признают наличие общих интересов и ценностей, при этом ограничивая себя правилами [5, р. 13]. В свою очередь к чертам международного порядка австралий- 
ский ученый относил стремление к сохранению существующей системы государств, взаимное признание суверенитета других акторов во внешнеполитической сфере, приверженность миру и безопасности при интеракции с другими агентами в качестве нормативного состояния (при наличии, однако, агрессивных модусов поведения в отдельные промежутки времени) и ограничение насилия на международной арене [5, p. 16].

Особое место в исследовании тематики границ сообщества и их нарушителей занимает конструктивистское течение теории международных отношений, представители которого обращают внимание на наличие в международной среде правил и норм, способствующих превращению системы государств в инстанцию ценностно-социетального характера. Так, А. Вендт выделяет сообщество государств и мировое сообщество в качестве стадий движения от хаотичного состояния «войны всех против всех» (соответствующего так называемой гоббсианской враждебной культуре анархии международных отношений) к мировому государству (кантианской партнерской культуре). Промежуточные инстанции несут в себе черты срединной в классификации Вендта локкианской культуры с ее признанием взаимного суверенитета, частичной кооперацией в рамках совместных институтов и зачатками коллективной идентичности [42]. С другой стороны, авторы концепции «жизненного цикла норм» М. Финнемор [12] и К. Сиккинк [30] в своих моделях утверждают либерально-демократические стандарты поведения как системообразующие для мирового порядка и эталонные, внедрению которых препятствуют ретроградные автократические режимы, зачастую представляющие собой анализируемые нами категории «изгоев».

Тем не менее группа вышеуказанных авторов, занимаясь вопросами границ сообщества и наличия аутсайдеров, не фокусирует свое внимание непосредственно на категории «стран-изгоев». Опуская проблему различных трактовок нормативных стандартов мирового порядка, неопределенным остается и ряд прочих ключевых моментов. Какова роль международного сообщества в присваивании государству статуса «изгоя»? Через какие конкретные каналы осуществляется процесс клеймения?
Каковы ключевые характеристики отношения мировой общественности к «отверженным» и их поведенческие модели? Для ответа на подобные вопросы целесообразно обратиться к генеалогии понятия «страны-изгоя» и его практическому воплощению во внешней политике государств как ключевых акторов международных отношений.

Сам термин «государств-изгоев» зародился в конце 70-х гг. в период президентства Дж. Картера после опубликования санкционного списка стран - спонсоров терроризма, куда вошли Южный Йемен, Ливия, Ирак и Сирия [1]. Впоследствии Куба и Иран получили подобный статус, а к критериям его присуждения добавилось стремление государства к незаконному приобретению оружия массового поражения [7]. По мнению советника У. Клинтона по национальной безопасности А. Лейка, «государства-изгои» в силу нарушений базовых прав человека и непредсказуемой внешней политики представляют собой опасность для международного сообщества, которому следует жестко реагировать на действия «отверженных» [22]. Отметим, что, получив широкое распространение в период правления демократической администрации [20], концепция достигла пика своего практического применения при Дж. Бушемладшем, благоволившем интервенционистским настроениям «ястребов» в Белом доме.

Параллельно становлению данного термина происходило конструирование смежных смысловых понятий, например, «оси зла», которое было озвучено Дж. Бушем в его речи от 29 января 2002 года. В список стран, занимающихся спонсированием международного терроризма и попытками незаконного приобретения оружия массового поражения, попали три «изгоя»- Иран, Ирак и Северная Корея [10]. Также целесообразно отметить родственную, но не равнозначную «странам-изгоям» категорию «государств-парий» («раriah states»); по мнению О. Лаваля, получение статуса первых зависит от поведенческих характеристик режима, в то время как к последним относятся государства, чьи происхождение, легитимность и идеология вызывают вопросы у международного сообщества [24].

С течением времени под давлением критики [9] и других обстоятельств термин«из- 


\section{ПОЛИТИЧЕСКИЕ НАУКИ И РЕГИОНОВЕДЕНИЕ}

гои» был заменен на «государства, вызывающие озабоченность» (states of concern) [27], однако множественность терминов для обозначения фигуры аутсайдера не должна вводить в заблуждение относительно содержательной стороны вопроса. Невозможно проигнорировать и непостоянство критериев отнесения акторов к категории «отверженных», что выливается уже в изменчивость формального списка аутсайдеров: так по линии законности обладания ядерным оружием (один из ключевых критериев признания страны «изгоем») в рассматриваемую категорию наряду с постоянными фигурантами включаются даже Израиль, Индия и Пакистан [19]. На рубеже первой и второй декады третьего тысячелетия концепция переживает период номинальной утраты прежнего влияния, однако международные санкции, будучи типичным инструментом борьбы с «отверженными» [32], часто нацелены именно на те государства, которым присваивается статус «изгоев». Таким образом, фактически рассматриваемая проблематика инсайдеров и аутсайдеров международного сообщества не теряет своей актуальности в связи с терминологическими флуктуациями в политическом и научном дискурсе Запада.

Итак, резюмируя основные контуры существующего академического знания относительно концепции «стран-изгоев» и ее связи с проблематикой аутсайдерства в мировом сообществе, возможно выделить три пункта. Вопервых, рассматриваемая категория несет дискриминационное смысловое содержание, которое выливается в практические политические последствия для всех сторон взаимодействия. Во-вторых, как формальные границы этого понятия, так и его наполнение расплывчаты и непостоянны. В-третьих, благодаря вкладу Английской школы и конструктивистского направления теории международных отношений можно констатировать социетальное происхождение критериев формирования группы «изгоев». Однако в силу различных обстоятельств данная проблематика остается малоизученной и, как следствие, даже у современных направлений теории не хватает концептуального арсенала для адекватного осмысления роли сообщества государств в определении рамок нормативности, его отно- шения к нарушителям этих международных стандартов и, наконец, поведенческих характеристик «изгоев». Очевидным атрибутом взаимодействия выступает прежде всего отчуждение и дискриминация, которые отсылают к идее стигматизации, негативного отношения общества к индивиду или социальной группе на основе нежелательной черты в моральном или телесном облике.

Понятие «стигмы» обладает богатой ретроспективой исследований в социологии, психологии и психиатрии, однако ключевая роль в его развитии и разработке принадлежит американскому ученому И. Гофману, опубликовавшему в 1963 г. свой программный труд «Стигма: заметки об управлении испорченной идентичностью» [14]. И. Гофман указывает на общество в качестве инстанции, устанавливающей границы нормативного поведения индивидов, а характеристики относительно должного образа действий называет виртуальной социальной идентичностью [14, p. 12]. При этом зачастую последняя не совпадает с истинной социальной идентичностью, что в массовом сознании «из цельного обычного человека [превращает его] в неполноценного, обладающего каким-то дефектом, подпорченного» [14, p. 12-13]. Диапазон критериев для присуждения статуса стигмы варьируется от негативных телесных характеристик (длинный нос) до несоответствия социально-желательному моральному облику (гомосексуализм) или принадлежности к определенным этническим группам (еврейское происхождение) [14, p. 14].

Однако до описания непосредственных особенностей функционирования моделей отчуждения необходимо выявить способы включения индивидов/государств в данные категории. Социологическая «теория клеймения» (Labelling theory) [3; 25] располагает обширным эпистемологическим арсеналом для осуществления подобных операций: американский исследователь Г. Беккер в своей классической книге «Аутсайдеры» описал полноценный механизм присваивания индивидам стигматизированного статуса.

Несмотря на наличие влиятельной и идущей от Т. Гоббса и Г. Гегеля традиции антропоморфизации государства, необходимо подчеркнуть невозможность механического 
перенесения подобной логики, присущей межличностному взаимодействию или отношениям определенных социальных групп, на комплексные политические сообщества, которыми являются государства. Тем не менее А. Вендт, и вовсе оправдывая подобный прием, указывает на присущую государству интенциональность и сравнивает его с комплексным организмом (например, улеем) [41]. Более того, применяя модели символического интеракционизма по описанию формирования личностной идентичности (взаимодействие альтер и эго) к генезису идентичностей на уровне государств [40], А. Вендт добивается выдающихся эпистемологических результатов, выводя теоретическое осмысление взаимодействия государств на новый уровень.

Подобным образом, не применяя модели И. Гофмана и Г. Беккера буквально, представляется продуктивным с опорой на эмпирический критерий провести параллели в процессе формирования статуса и идентичности «отверженного» между обществом и индивидом с одной стороны и между международным сообществом и отдельными государствами с другой. Пример включения Ирака в «зону отчуждения» после Войны в заливе 1991 г. будет призван продемонстрировать эффективность и целесообразность перенесения логики социологов на уровень межгосударственного взаимодействия.

Как и представители школ и направлений, задействующих социологический инструментарий для анализа международной среды, например, Хедли Булл [5] или конструктивисты [13], Г. Беккер утверждает, что именно общество устанавливает правила нормативного поведения, тем самым создавая девиацию [3, p. 8-9]. По мнению ученого, сам поступок в объективном смысле не может быть девиантным, таковым он становится лишь после общественной реакции на него, которая, отметим, может быть различной для одного и того же действия, будучи совершенным отличными акторами при уникальных обстоятельствах; общественная значимость понесшей ущерб стороны также должна быть принята во внимание [3, p. 10-12]. Аналогичным образом и государства осуществляют значимые символические жесты, например, нару- шают международное право без следующих за этим санкционных последствий от мирового сообщества. Так, США в свете напряженной геополитической ситуации на Ближнем Востоке, сложившейся после революции в Иране, ввода советских войск в Афганистан 1979 г. и угрозы перебоев в поставках нефти продолжительный период времени в сдержанно-нейтральном ключе взаимодействовали с Ираком, поддерживая его в Ирано-иракской войне 1980-1988 гг. в надежде смягчить авторитарный режим Саддама Хуссейна [4]. Основным событием для формирования того, что Г. Беккер называет девиантной карьерой, является первое крупное общественно порицаемое отклоняющееся действие («публичная инициация» девианта как такового), с последующей оценкой индивида как нарушителя правила. Социолог отмечает, что именно после пересечения этого первого порога статус индивида как отверженного становится доминирующим по отношению к остальным социальным ролям [3, p. 30-32]. Для Ирака С. Хуссейна подобным рубежом можно назвать Войну в заливе 1991 г., в ходе которой реакция международного сообщества выразилась в санкционированной ООН интервенции по освобождению оккупированного Кувейта. Однако, по мнению Р. Тиффена и Дж. Тота, еще более значимым фактором перехода в новую категорию стала развернутая Западом беспрецедентная информационная кампания [37], призванная демонизировать прежде всего С. Хуссейна и, более того, весь иракский народ [38].

Далее Г. Беккер отмечает такую характерную особенность подобного социетального статуса, как склонность формирования дальнейшей девиантной карьеры индивида в духе «самовоспроизводящегося пророчества» [3, p. 34]: индивид в своем последующем поведении начинает выполнять предписанную ему социумом роль, катализируя дальнейшее клеймение себя как отверженного и вызывая еще большую реакцию со стороны сообщества. Соответственно рассматриваемый момент выступает вторым ключевым порогом. Исследователь Дж. Пост подчеркивает, что по истечении некоторого времени С. Хуссейн благосклонно принял статус борца арабского мира с коллективным Западом, в глобальном 
масштабе навязывающем свою модель политического, экономического и культурного строя своим контрагентам [29]. Более того, ответные действия иракского лидера на меры по его сдерживанию в подавляющем большинстве случаев представляли собой именно ту модель поведения во внутренней политике, следование которой коалиция стремилась пресечь (массовые репрессии, манипуляции в СМИ и т. д.) [6]. Таким образом, С. Хуссейн с его режимом органично вписался в навязываемый ему имидж «изгоя и нарушителя правил». Г. Беккер завершает свое повествование о формировании девиантной карьеры описанием фазы вступления «аутсайдера» в группу ему подобных [3, p. 37]; уже на предыдущем этапе возвращение к нормативному поведению и общественному имиджу является маловероятным исходом, а будучи частью организации стигматизированных, индивид и вовсе теряет эту возможность.

При этом демонстрация двух порогов включения государства в ранг «отверженных» возможна не только на примере Ирака, но и любых других фигурантов списка «изгоев». Для Ирана «публичной инициацией» стала революция 1979 г. с последующим конструированием западными СМИ образа страны на международной арене как классического «другого», которому присущи негативные черты зла, насилия и др. по контрасту с положительными атрибутами Запада [18]. В свою очередь враждебные действия США лишь катализировали эффект самовоспроизводящегося пророчества, укрепив внутреннее единство Ирана относительно внешнеполитического курса [16]. Подобным образом и КНДР получила статус «изгоя» в 1950 г. во время Корейской войны. США заклеймили Пхеньян как нарушителя международных норм, активировав первый порог процесса включения государства в ранг отверженных, но вместе с тем «стигма просуществовала до наших дней» [31], явившись свидетельством пересечения уже второго порога того, что Г. Беккер называл девиантной карьерой.

После поэтапного обозначения особенностей присуждения индивиду/государству статуса отверженного целесообразно вернуться к труду И. Гофмана для выявления ключевых параметров поведения стигматизи- рованного агента и отношения общества к нему. Американский социолог пишет о двух основополагающих чертах восприятия социумом человека со стигмой: с одной стороны его окружение стремится с помощью благожелательного социального действия смягчить и сгладить негативные нюансы неполноценности, а с другой, предполагая, что подобный индивид - «не совсем человек», применяет определенные формы дискриминации по отношению к нему [14, p. 15].

В связи с разностями особенностей уровней анализа и агент-системных структур при трансфере данной модели из мира межличностного взаимодействия в сферу международных отношений необходимо осуществить небольшую корректировку: стигматизированные государства могут сталкиваться с дискриминацией и повышенным вниманием глобального сообщества, но не с заведомо благожелательным отношением. Отметим, что «страны-изгои» претерпевают негативные последствия собственного статуса в виде санкционного давления, стремления исключить их из мирового порядка и даже угрозы прямой интервенции на основании их ненормативности и непредсказуемого поведения на международной арене $[7 ; 32 ; 35]$. Применительно ко второму критерию стигматизации подчеркнем, что на практике к «странам-изгоям» приковано повышенное внимание мирового сообщества, выливающееся в представленную как исходящую от них угрозу безопасности [39] на основе конструирования негативного имиджа [17], зачастую при отсутствии видимых различий с другими нестигматизированными авторитарными режимами, а также бесспорных статистических доказательств агрессивности «изгоев» [7].

Модель И. Гофмана примечательна и другими ее гипотезами относительно взаимодействия стигматизированных индивидов с окружающим миром. Так, социолог упоминает две группы, обладающие особым влиянием на их поведение: «свои», также отверженные и «понимающие» (wise) - нормальные люди, в силу специфической ситуации или своего прошлого посвященные в круг стигматизированных и симпатизирующие им [14, p. $31-$ 45]. Примером сотрудничества внутри первой категории на межгосударственном уровне 
может служить зачастую бессознательное благоволение режимов, схожих по стилю правления, друг другу с целью сохранения предсказуемой и гомогенной для себя окружающей среды [2], а именно усилия бывшего президента Венесуэлы У. Чавеса по выстраиванию международной кооперации практически со всеми «изгоями» [21].

В свою очередь внешнеполитический курс гибридного социалистического Китая располагает сходными эмпирическими атрибутами с поведением «понимающих». Будучи полноценным членом мирового сообщества, Пекин сохраняет тесные взаимоотношения с коммунистической Северной Кореей [36], несмотря на кажущуюся целесообразность сотрудничества с Сеулом, учитывая более значительный размер торговли с Южной Кореей [26]. Сходным образом Китай активно развивает свои отношения и с другими «изгоями» - с 2000 по 2008 г. двусторонняя торговля с Кубой выросла с 10 до 143 млрд долларов [15]. Причем Китай даже в условиях давления США и Евросоюза на Иран в связи с ядерной программой последнего оказывает многостороннюю поддержку Тегерану; более того, интенсивность кооперации в ряде сфер позволяет говорить о долгосрочном и устойчивом характере сотрудничества двух государств [8].

Отметим, что конкретные возможности применения концепций американского социолога не ограничиваются вышеобозначенными примерами. Анализируя поведение стигматизированных индивидов, И. Гофман замечает их поведенческую неустойчивость: резкий переход от внутренне сжатого состояния к подчеркнутой браваде [14, p. 29], что обладает определенными параллелями с внешней политикой «стран-изгоев», например, Ирана, внешнеполитический курс которого колеблется между агрессивными попытками разработки ядерного оружия и примирительными периодами взаимодействия с Западом под гнетом санкций международного сообщества [28]. Более того, дальнейшего изучения требуют перспективы проецирования логики стигматизации на других членов международного сообщества государств: И. Гофман пишет о стремлении стигматизированных индивидов к получению «вторичных выгод» [14, p. 21], которые те используют для извлечения так на- зываемых неконкурентных преимуществ на основании собственной неполноценности. Исследователи Ф. Шиммельфениг и А. Лазас показали, как страны Центральной и Восточной Европы [23; 34] вполне в духе стигматизации использовали апелляцию к предательству их Западом 50-летней давности в ходе Мюнхенского сговора и Ялтинской конференции, а также постулирование общей с Европой идентичности для форсирования вступления в ЕС и НАТО. Подобный ход может трактоваться социологами именно как получение вторичной выгоды на основе стигматизированной черты (коммунистическое прошлое).

Итак, благодаря применению социологического концептуального арсенала И. Гофмана и Г. Беккера на эмпирическом примере внешнеполитического курса Ирака после войны в Заливе 1991 г. были продемонстрированы два порога включения государства в группу «изгоев»: «публичная инициация» нарушителя и «самовоспроизводящееся пророчество», после которого девиантная карьера становится практически неизбежной. Более того, данная статья призывает к более активному соотнесению атрибутов и интеракционных модусов межличностного/межгруппового и транснационального взаимодействия. Среди характерных поведенческих характеристик аутсайдера можно выделить высокую степень кооперации с представителями собственной категории, «неустойчивую браваду» и стремление к получению вторичных выгод, связанных со стигматизированным статусом. В свою очередь глобальное сообщество склонно к проявлению повышенного внимания к «изгоям» и их дискриминации на основе ненормативного положения в международной структуре; исключение составляет группа «понимающих» участников мирового порядка, располагающих более тесными, чем остальные, связями с аутсайдерами. Несмотря на отдельные попытки использования концепций И. Гофмана для объяснения мировой политики [33], эпистемологические возможности импликации его идеи стигмы и «теории клеймения» Г. Беккера и Э. Лемерта остаются практически незадействованными учеными теории международных отношений. Однако подобный импорт моделей из социологии имеет обширный потенциал для улучшения академи- 
ческого осмысления проблематики инсайдерства и аутсайдерства в международном сообществе путем выделения прежде неочевидных черт интеракции контрагентов и поведенческих характеристик стигматизированных членов мирового порядка.

\section{СПИСОК ЛИТЕРАТУРЫ}

1. Бартенев, В. Концепция «государств-изгоев» во внешней политике США / В. Бартенев // Международные процессы. - 2009. - Т. 7, № 1 (19). C. $84-92$.

2. Bader, J. Would autocracies promote autocracy? A political economy perspective on regime-type export in regional neighbourhoods / J. Bader, J. Grävingholt, J. Kästner // Contemporary Politics. - 2010. - Vol. 16, № 1. - P. 81-100.

3. Becker, H. S. Outsiders. Studies in the sociology of deviance/ H. S. Becker. - N. Y. : Free Press, 2008. $-224 \mathrm{p}$.

4. Brands, H. Before the tilt: the Carter administration engages Saddam Hussein / H. Brands // Diplomacy \& Statecraft. -2015. - Vol. 26, № 1. -P. 103-123.

5. Bull, H. The anarchical society: a study of order in world politics / H. Bull. - L. : Palgrave Macmillan, 2002. $-368 \mathrm{p}$.

6. Byman, D. Coercing Saddam Hussein: lessons from the past / D. Byman, K. Pollack, M. Waxman // Survival. - 1998. - Vol. 40, № 3. - P. 127-151.

7. Caprioli, M. Rhetoric versus reality rogue states in interstate conflict/ M. Caprioli, P. F. Trumbore // Journal of Conflict Resolution. - 2005. - Vol. 49, № 5. - P. 770-791.

8. Currier, C. L. In arms we trust: The economic and strategic factors motivating China-Iran relations / C. L. Currier, M. Dorraj // Journal of Chinese Political Science. - 2010. - Vol. 15, № 1. - P. 49-69.

9. Derrida, J. Rogues: Two essays on reason / J. Derrida. - Stanford : Stanford University Press, 2005. $-175 \mathrm{p}$.

10. Di Filippo, A. US policy and the nuclear weapons ambitions of the «Axis of Evil» countries /A. Di Filippo// New Political Science.-2006. - Vol. 28, № 1. - P. 101-123.

11. Doyle, M. W. Kant, liberal legacies, and foreign affairs, part 2 / M. Doyle // Philosophy \& Public Affairs. - 1983. - Vol. 12, № 4. - P. 323-353.

12. Finnemore, M. International norm dynamics and political change / M. Finnemore, K. Sikkink // International Organization. - 1998. - Vol. 52, № 04. P. 887-917.

13. Geldenhuys, D. Beyond the rogue state paradigm / D. Geldenhuys // South African Journal of International Affairs. - 2002. - Vol. 9, № 1. - P. 75-88.
14. Goffman, E. Stigma: notes on the management of spoiled identity/ E. Goffman. - L. : Penguin, 1963.-155 p.

15. Hearn, A. H. Cuba and China: governance and industrial collaboration / A. H. Hearn // Journal of Iberian and Latin American Research. - 2009. - Vol. 15, № 2. - P. 65-81.

16. Heradstveit, D. What the axis of evil metaphor did to Iran / D. Heradstveit, M. G. Bonham // The Middle East Journal. - 2007. - Vol. 61, № 3. - P. 421-440.

17. Hoyt, P. D. The 'rogue state' image in American foreign policy / P. D. Hoyt // Global Society. - 2000. - Vol. 14, № 2. - P. 297-310.

18. Jahedi, M. The ideological construction of Iran in the NYT / M. Jahedi, F. S. Abdullah // Australian Journal of Linguistics. -2012. - Vol. 32, № 3. - P. 361-381.

19. Kapur, A. Rogue states and the international nuclear order / A. Kapur // International Journal. 1996. - Vol. 51, № 3. - P. 420-439.

20. Klare, M. The rise and fall of the «rogue doctrine» / M. Klare // Middle East Report. - 1998. № 208. - P. 12-15.

21. Kucera, J. What is Hugo Chávez up to? / J. Kucera // The Wilson Quarterly. - 2011. - Vol. 35, № 2. - P. 22-30.

22. Lake, A. Confronting Backlash States / A. Lake // Foreign Affairs. - 1994. - Vol. 73, № 2. - P. 45-55.

23. Lasas, A. Restituting victims: EU and NATO enlargements through the lenses of collective guilt / A. Lasas // Journal of European Public Policy. - 2008. Vol. 15, № 1.- P. 98-116.

24. Lawal, O. Pariah state system and enforcement mechanism of international law / O. Lawal // Journal of Alternative Perspectives in the Social Sciences. - 2012. Vol. 4, № 1. - P. 226-241.

25. Lemert, E. M. Human deviance, social problems, and social control / E. M. Lemert. - Englewood Cliffs : Prentice-Hall, 1972. $-224 \mathrm{p}$.

26. Nanto, D. K. The effect of the rise of China on Taiwan, Japan, and South Korea / D. K. Nanto, E. Chanlett-Avery// Problems of Post-Communism. 2006. - Vol. 53, № 1. - P. 33-47.

27. O'Sullivan, M. L. Replacing the rogue rhetoric: A new label opens the way to a better policy / M. L. O'Sullivan // The Brookings Review. - 2000.Vol. 18, № 4. - P. 38-40.

28. Perthes, V. Ambition and fear: Iran's foreign policy and nuclear programme / V. Perthes // Survival. 2010. - Vol. 52, № 3. - P. 95-114.

29. Post, J. M. Saddam Hussein of Iraq: A political psychology profile / J. M. Post // Political Psychology. 1991. - Vol. 12, № 2. - P. 279-289.

30. Risse, $T$. The socialization of international human rights / T. Risse, K. Sikkink // The power of human rights: international norms and domestic change / ed. by T. Risse, S. C. Ropp, K. Sikkink. - Cambridge : Cambridge University Press, 1999. 
31. Roy, D. North Korea as an alienated state / D. Roy // Survival. - 1996. - Vol. 38, № 4. - P. 22-36.

32. Saunders, E. N. Setting boundaries: Can international society exclude «rogue states»? / E. N. Saunders // International Studies Review. 2006. - Vol. 8, № 1. - P. 23-54.

33. Schimmelfennig, F. Goffman meets IR: dramaturgical action in international community / F. Schimmelfennig // International Review of Sociology. - 2002. - Vol. 12, № 3. - P. 417-437.

34. Schimmelfennig, F. The community trap: Liberal norms, rhetorical action, and the Eastern enlargement of the European Union / F. Schimmelfennig // International organization. - 2001. - Vol. 55, № 01. P. 47-80.

35. Schwartz, J. B. Dealing with a «rogue state»: the Libya precedent / J. B. Schwartz // American Journal of International Law. - 2007. - Vol. 101, № 3.P. 553-580.

36. Song, J. Understanding China's response to North Korea's provocations / J. Song // Asian Survey. 2011. - Vol. 51, № 6. - P. 1134-1155.

37. Tiffen, R. Marching to whose drum? Media battles in the GulfWar / R. Tiffen // Australian Journal of International Affairs. - 1992. - Vol. 46, № 1. - P. 44-60.

38. Toth, J. Demonizing Saddam Hussein: Manipulating racism as a prelude to war / J. Toth // New Political Science. - 1992. - Vol. 11, № 1-2. - P. 5-39.

39. Veit, R. When good states go bad / R. Veit // AQ: Journal of Contemporary Analysis. - 2003. Vol. 75, № 2. - P. 33-40.

40. Wendt, A. Anarchy is What states make of it: the social construction of power politics / A. Wendt // International organization. - 1992. - Vol. 46, № 02. P. 391-425.

41. Wendt, A. The state as person in international theory / A. Wendt // Review of International Studies. 2004. - Vol. 30, № 2. - P. 289-316.

42. Wendt, A. Why a world state is inevitable / A. Wendt // European Journal of International Relations. - 2003. - Vol. 9, № 4. - P. 491-542.

\section{REFERENCES}

1. Bartenev V. Kontseptsiya «gosudarstv-izgoev» vo vneshney politike SShA [The Concept of "Rogue States" in Foreign Policy of the USA]. Mezhdunarodnye protsessy, 2009, vol. 7, no. 1 (19), pp. 84-92.

2. Bader J., Grävingholt J., Kästner A. Would autocracies promote autocracy? A political economy perspective on regime-type export in regional neighbourhoods. Contemporary Politics, 2010, vol. 16 , no. 1 , pp. 81-100.

3. Becker H.S. Outsiders. Studies in the sociology of deviance. New York, Free Press, 2008. 224 p.
4. Brands H. Before the Tilt: The Carter Administration Engages Saddam Hussein. Diplomacy \& Statecraft, 2015, vol. 26, no. 1, pp. 103-123.

5. Bull H. The anarchical society: a study of order in world politics. London, Palgrave Macmillan, 2002.368 p.

6. Byman D., Pollack K., Waxman M. Coercing Saddam Hussein: lessons from the past. Survival, 1998, vol. 40, no. 3, pp. 127-151.

7. Caprioli M., Trumbore P.F. Rhetoric versus Reality Rogue States in Interstate Conflict. Journal of Conflict Resolution, 2005, vol. 49, no. 5, pp. 770-791.

8. Currier C.L., Dorraj M. In arms we trust: The economic and strategic factors motivating China-Iran relations. Journal of Chinese Political Science, 2010, vol. 15 , no. 1, pp. 49-69.

9. Derrida J. Rogues: Two essays on reason. Stanford, Stanford University Press, 2005. 175 p.

10. Di Filippo A. US Policy and the Nuclear Weapons Ambitions of the "Axis of Evil" Countries. New Political Science, 2006, vol. 28, no. 1, pp. 101-123.

11. Doyle M.W. Kant, liberal legacies, and foreign affairs, part 2. Philosophy \& Public Affairs, 1983, vol. 12 , no. 4, pp. 323-353.

12. Finnemore M., Sikkink K. International norm dynamics and political change. International organization, 1998, vol. 52, no. 4, pp. 887-917.

13. Geldenhuys D. Beyond the rogue state paradigm. South African Journal of International Affairs, 2002, vol. 9, no. 1, pp. 75-88.

14. Goffman E. Stigma: Notes on the Management of Spoiled Identity. London, Penguin, 1963. 155 p.

15. Hearn A.H. Cuba and China: Governance and Industrial Collaboration. Journal of Iberian and Latin American Research, 2009, vol. 15, no. 2, pp. 65-81.

16. Heradstveit D., Bonham M.G. What the axis of evil metaphor did to Iran. The Middle East Journal, 2007, vol. 61, no. 3, pp. 421-440.

17. Hoyt P.D. The 'rogue state' image in American foreign policy. Global Society, 2000, vol. 14, no. 2, pp. 297-310.

18. Jahedi M., Abdullah F.S. The ideological construction of Iran in The NYT. Australian Journal of Linguistics, 2012, vol. 32, vol. 3, pp. 361-381.

19. Kapur A. Rogue states and the international nuclear order. International Journal, 1996, vol. 51, no. 3, pp. 420-439.

20. Klare M. The Rise and fall of the "Rogue Doctrine". Middle East Report, 1998, no. 208, pp. 12-15.

21. Kucera J. What is Hugo Chávez up to? The Wilson Quarterly, 2011, vol. 35, no. 2, pp. 22-30.

22. Lake A. Confronting Backlash States. Foreign Affairs, 1994, vol. 73, no. 2, pp. 45-55.

23. Lasas A. Restituting victims: EU and NATO enlargements through the lenses of collective guilt. 


\section{ПОЛИТИЧЕСКИЕ НАУКИ И РЕГИОНОВЕДЕНИЕ}

Journal of European Public Policy, 2008, vol. 15, no. 1, pp. 98-116.

24. Lawal O. Pariah State System and Enforcement Mechanism of International Law. Journal of Alternative Perspectives in the Social Sciences, 2012, vol. 4, no. 1, pp. 226-241.

25. Lemert E.M. Human deviance, social problems, and social control. Englewood Cliffs, Prentice-Hall, 1972. 224 p.

26. Nanto D.K., Chanlett-Avery E. The effect of the rise of China on Taiwan, Japan, and South Korea. Problems of Post-Communism, 2006, vol. 53, no. 1, pp. 33-47.

27. O'Sullivan M.L. Replacing the rogue rhetoric: A new label opens the way to a better policy. The Brookings Review, 2000, vol. 18, no. 4, pp. 38-40.

28. Perthes V. Ambition and fear: Iran's foreign policy and nuclear programme. Survival, 2010, vol. 52, no. 3, pp. 95-114.

29. Post J.M. Saddam Hussein of Iraq: A political psychology profile. Political Psychology, 1991, vol. 12, no. 2, pp. 279-289.

30. Risse T., Sikkink K. The socialization of international human rights. Risse T., Ropp S.C., Sikkink K., eds. The power of human rights: international norms and domestic change. Cambridge, Cambridge University Press, 1999.

31. Roy D. North Korea as an alienated state. Survival, 1996, vol. 38, no. 4, pp. 22-36.

32. Saunders E.N. Setting Boundaries: Can International Society Exclude "Rogue States"? International Studies Review, 2006, vol. 8, no. 1, pp. 23-54.
33. Schimmelfennig F. Goffman meets IR: dramaturgical action in international community. International Review of Sociology, 2002, vol. 12, no. 3, pp. 417-437.

34. Schimmelfennig F. The community trap: Liberal norms, rhetorical action, and the Eastern enlargement of the European Union. International organization, 2001, vol. 55, no. 1, pp. 47-80.

35. Schwartz J.B. Dealing with a "rogue state": the Libya precedent. American Journal of International Law, 2007, vol. 101, no. 3, pp. 553-580.

36. Song J. Understanding China's Response to North Korea's Provocations. Asian Survey, 2011, vol. 51, no. 6, pp. 1134-1155.

37. Tiffen R. Marching to whose drum? Media battles in the Gulf War. Australian Journal of International Affairs, 1992, vol. 46, no. 1, pp. 44-60.

38. Toth J. Demonizing Saddam Hussein: Manipulating racism as a prelude to war. New Political Science, 1992, vol. 11, no. 1-2, pp. 5-39.

39. Veit R. When Good States Go Bad. $A Q$ : Journal of Contemporary Analysis, 2003, vol. 75, no. 2, pp. 33-40.

40. Wendt A. Anarchy is what states make of it: the social construction of power politics. International organization, 1992, vol. 46, no. 2, pp. 391-425.

41. Wendt A. The state as person in international theory. Review of International Studies, 2004, vol. 30, no. 2, pp. 289-316.

42. Wendt A. Why a world state is inevitable. European journal of international relations, 2003, vol. 9 , no. 4 , pp. 491-542.

\section{Information about the Author}

Gleb V. Kotsur, Master Student, Department of Theory and History of International Relations, Saint Petersburg State University, Smolnogo St., 1/3, 191060 Saint Petersburg, Russian Federation, glebk17@gmail.com, http://orcid.org/0000-0003-4079-264X.

\section{Информация об авторе}

Глеб Владиславович Коцур, магистрант кафедры теории и истории международных отношений, Санкт-Петербургский государственный университет, ул. Смольного, 1/3, 191060 г. СанктПетербург, Российская Федерация, glebk17@gmail.com, http://orcid.org/0000-0003-4079-264X. 